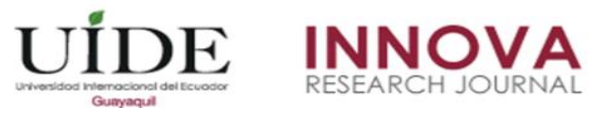

INNOVA Research Journal, ISSN 2477-9024

(Mayo, 2017). Vol. 2, No.5 pp. 163-189

DOI: https://doi.org/10.33890/innova.v2.n5.2017.171

URL: http://revistas.uide.edu.ec/index.php/innova/index

Correo: innova@uide.edu.ec

\title{
Mecanismos para el rescate de cultivos autóctonos en la comunidad de Tuncarta, cantón Saraguro, provincia de Loja
}

\section{Mechanisms for the rescue of autochthonous crops in the community of Tuncarta, Saraguro canton, province of Loja}

\author{
Pablo Antonio Abrigo Córdova \\ Universidad Internacional del Ecuador, Ecuador
}

Autores para correspondencia: egtmaloja@gmail.com

Fecha de recepción: 20 de Febrero de 2017 - Fecha de aceptación: 28 de Abril de 2017

Resumen: En el cantón Saraguro, a diferencia de otras zonas de producción, nace un conjunto analítico a partir de una realidad étnica que condiciona las prácticas y comportamientos de la población del lugar. En esta zona, aparecen juntas por primera vez, a más de los tubérculos andinos o autóctonos, asociaciones que no son comunes, y dentro de una lógica de diversificación que parece estar más viva que otros espacios indígenas. Entre los problemas para la producción y el abandono de los cultivos andinos o autóctonos se incluye la pérdida de la fertilidad del suelo, pérdida del conocimiento ancestral sobre el manejo, escasez de mano de obra, falta de asesoramiento técnico; así como desvalorización de las propiedades nutritivas, siendo el resultado de un proceso de aculturación que han sufrido éstos productos (Abrigo, 2016). Debido a éstos antecedentes, el presente trabajo pretende diseñar e implementar un Proyecto de Intervención Comunitaria que permita potenciar el rescate de los cultivos autóctonos en el sector de Tuncarta, el cual se sustenta en un plan de actividades que permitan resolver la problemática planteada a desarrollarse a corto y largo plazo, en donde se enfatiza todo el proceso del autodesarrollo que va desde la participación, cooperación y conciencia crítica de los habitantes (Abrigo, 2012).

Palabras claves: cultivo autóctono; desarrollo comunitario; MDP

Abstract: In the Saraguro canton, unlike other areas of production, an analytical set is born out of an ethnic reality that conditions the practices and behaviors of the local population. In this area, for the first time, more than the Andean or indigenous tubers appear, associations that are not common, and within a logic of diversification that seems to be more alive than other indigenous spaces. Problems for the production and abandonment of native crops include loss of soil fertility, loss of ancestral knowledge about management, labor shortages, lack of technical advice; As well as devaluation of the nutritional properties, being the result of a process of acculturation suffered by these products (Abrigo, 2016). Due to these antecedents, the present work intends to design and implement a Community Intervention Project that allows to promote the rescue of the native crops in the sector of Tuncarta, which is based on a plan of activities that allow to solve the problem raised to develop to Short and long term, emphasizing the whole process of self-development that goes from participation, cooperation and critical awareness of the inhabitants (Abrigo, 2012).

Key words: autochthonous cultivation; community development; MDP 


\section{Introducción}

Pérdida de los cultivos originarios en la comunidad de Tuncarta: Los cultivos autóctonos han jugado un papel fundamental en el desarrollo de las culturas andinas. Desde que el hombre llegó a esta región hace aproximadamente 10.000 años ha utilizado los recursos vegetales como fuente de alimento, medicinas, combustible, materiales de construcción y herramientas de todo tipo; las plantas han ocupado incluso un lugar importante en su sistema de creencias y ritos. Estos recursos se obtuvieron en un inicio solamente de recolección de plantas silvestres, más con el tiempo se desarrolló una avanzada agricultura que utilizó tecnologías, como las terrazas y camellones y que permitió la sedentarización y evolución cultural en la región.

En este contexto, a lo alto de los Andes al sur del Ecuador, entre las provincias de Azuay y Loja, se ubica el cantón Saraguro. Ahí viven los Saraguros, una cultura indígena bien conocida por su bien preservada forma de vida, su ropa y artesanía tradicional, su lengua quichua y su gastronomía. El pueblo Saraguro mantiene orgulloso, los cohesivos culturales que han estructurado su vida por cientos de años.

Uno de los principales problemas que aquejan al cantón Saraguro y en particular la comunidad de Tuncarta, es la carencia de tierras cultivables y productivas que faciliten una mejor producción de los cultivos autóctonos; así como desconocimiento de la fertilización apropiada del suelo y la falta de material de siembra, estos inconvenientes fueron el primer aspecto negativo que influyó para que en los años 80 se produzca una migración temporal de los Saraguros hacia las minas de Nambija y Bella Rica; la prestación de mano de obra en las construcciones de Quito, Cuenca y Guayaquil y un abandono total de los cultivos nativos.

Además, otro factor importante a destacar es que no existen trabajos investigativos, sobre el manejo de este tipo de cultivos y de los pocos no existe difusión, lo que ha propiciado poca importancia en el sector, en toda la provincia de Loja y a nivel nacional; ya sea por el escaso conocimiento de variedades con buen rendimiento y por la falta de información sobre las bondades nutricionales y medicinales de estos cultivos en la alimentación humana y sus formas de procesamiento.

Otra de las razones para que agricultores mestizos e indígenas del sector de Tuncarta hayan reducido o hasta eliminado los cultivos autóctonos es el precio poco competitivo que tiene en relación a otros productos agrícolas; ya que, los precios de la mayoría de tubérculos tradicionales son muy insignificantes y no representan realmente la inversion realizada, por lo que económicamente no es rentable su producción. Al tema de costos y precios, se suma lo complejo que resulta introducir este alimento en el mercado urbano. Por otro lado, no existe estudio que avale las características medicinales (antiinflamatorias, reumáticas, desinfectantes, etc.) que se les atribuyen y una limitada demanda.

Según Abrigo (2016), en su trabajo investigativo: La producción orgánica del melloco y su rentabilidad en la comunidad de Tuncarta, manifiesta que, la pérdida de los cultivos autóctonos se debe a que éstas especies han sufrido un proceso de erosión resultado de la aculturación alimenticia de los pueblos indígenas. Es decir, la disminución del consumo por la aculturación que ha sufrido la población, mediante el reemplazo de los alimentos tradicionales 
por otros tipos de alimentos no tradicionales, por otros que en la mayoría son de menor nivel nutritivo. Estos cambios de hábitos alimenticios ha provocado la disminución de la demanda y oferta de los tubérculos.

Para definir los principales problemas que necesitan solución, los cuales son de real importancia en la investigación, fue necesario aplicar una matriz para el diagnóstico participativo (MDP) (Abrigo, 2012) a los moradores del sector de Tuncarta, la cual nos sirvió para determinar sus malestares y priorizarlos mediante la ejecución de proyectos. Además nos permitió conocer cuáles han sido las causas y los efectos que han generado este tipo de problemas. Esta actividad se la realizó mediante la aplicación de grupos focales, de discusión, entre otros.

Desde este enfoque, se pudo identificar en el trabajo investigativo, el siguiente problema: ¿Cómo contribuir al rescate de los cultivos autóctonos en el sector de Tuncarta propiciando técnicas adecuadas de producción y procesamiento mediante procesos de intervención profesional?

Es por ello, que mediante el presente trabajo, se hace necesario dar solución a ésta problemática proponiendo un programa de intervención comunitaria para rescatar los cultivos autóctonos y así obtener mayor valor agregado. De esta manera se aplicò una estrategia de comunicación que nos facilitó el involucramiento en la cotidianidad y sus aspectos socioculturales más relevantes. Además nos permitió recomendar a la población indígena ciertos mecanismos de producción orgánica de cultivos aborígenes y sus formas de procesamiento, lo que implica, un aumento de la producción e ingresos económicos en los habitantes del sector en estudio.

Sin embargo, en los últimos años no se ha realizado investigación alguna debido a la poca importancia que se le da en nuestra provincia a los cultivos aborígenes, ya que muchos agricultores desconocen sus propiedades alimenticias y medicinales, las variedades, el manejo y por ende la rentabilidad. Siendo un factor principal para que en nuestra provincia, en especial en el sector en estudio, la oferta y la demanda sean casi nulas generando el abandono de éstos cultivos.

Es por ello que resulta de real importancia, apoyar a este tipo de proyectos, ya que se pone de manifiesto la vinculación de interesados en el tema, como gestores socioculturales, con la comunidad que será beneficiada. Por este motivo se pretende saber si existe la posibilidad de proponer una fundamentación metodológica desde la perspectiva de la intervención comunitaria y potenciar el rescate de los cultivos autóctonos en Tuncarta.

El valor metodológico de la presente investigación, estuvo en la aplicación de una metodología de autodesarrollo comunitario que potenció los procesos de participación, cooperación, conciencia crítica y la consecución definitiva del proyecto gestado por la comunidad, lo que permitirá a futuro rescatar los cultivos ancestrales. Además, el valor social, está en los beneficios que representa para la comunidad el rescate de éstos cultivos, principalmente la mashua, melloco, la zanahoria blanca y la oca.

\section{Para el desarrollo del presente trabajo investigativo se plantearon los siguientes objetivos:}




\section{Objetivo Primario:}

- Gestar un proyecto de autodesarrollo para potenciar el rescate de los cultivos autóctonos en los habitantes del sector Tuncarta del cantón Saraguro.

\section{Objetivo Secundario:}

- Diagnosticar el estado actual de la producción de los cultivos autóctonos.

- Diseñar un proyecto de intervención, con énfasis en el paradigma de autodesarrollo gestado por la comunidad.

Hipótesis: La producción de cultivos autóctonos ha disminuido sustancialmente, motivado por diferentes factores económicos, sociales y culturales en el sector de Tuncarta, lo cual puede ser mejorado si se potencia el rescate de los cultivos autóctonos en el sector.

Los objetivos e hipótesis de la presente investigación están relacionados directamente, porque, se podrá proponer el rescate de los cultivos originarios, a través de la concientización en los productores en el uso de técnicas adecuadas de producción y procesamiento de estos cultivos desde el enfoque del autodesarrollo comunitario.

Explore la Importancia del problema: Para proponer mecanismos de rescate de cultivos originarios o autóctonos en la comunidad de Tuncarta, se propuso una fundamentación metodológica desde la perspectiva de la intervención comunitaria (Martínez, 2011) que consintió en realizar talleres autodirigidos, lo que facilitó los procesos de participación, cooperación conciencia crítica y la consecución definitiva del proyecto gestado por la comunidad (Freire, 2010). Finalmente hay que considerar que la MDP fue muy útil, porque, permitió la identificación de problemas que propiciaron el abandono de los cultivos autóctonos.

\section{Métodos}

Los métodos científicos que se utilizaron en la presente investigación fueron desglosados de la siguiente manera:

Análisis - Síntesis: Permitió analizar principales elementos del desarrollo comunitario así como la participación y cooperación.

Inducción - Deducción: Para analizar la participación fue necesario partir del desarrollo comunitario en general y luego se analizó la misma en el contexto de la producción y rescate con enfoque de procesamiento de los cultivos autóctonos del sector en estudio.

Histórico - Lógico: Se partió de la organización y análisis de la evolución histórica de los principales conceptos que aquí se tienen en cuenta (Desarrollo Comunitario, y manejo de cultivos autóctonos) para visualizar la trayectoria real de las causas y efectos que han generado el abandono de éstos cultivos.

Las técnicas utilizadas se detallan a continuación: 
La observación: Visualizó la realidad del hecho a investigar.

La encuesta: Se la empleó para investigar masivamente determinados hechos o fenómenos que han propiciado el abandono de los cultivos en el sector. El tipo de encuestas aplicadas fueron anónimas y las preguntas se desarrollaron de forma abierta y cerrada, para lo cual se les solicitó ayuda para la contestación de las preguntas que se encuentran impresas en un cuestionario.

La entrevista a profundidad : Se la realizó a dos representantes de organismos de apoyo social y a miembros de la comunidad de Tuncarta (dos consumidores y un productor) a los cuales se los consideró como informantes claves, por ser hombres y mujeres de sabiduría y conocer las actividades del sector. Con las opiniones vertidas en la entrevista se elaboró una valoración sobre su situación, determinando sus potencialidades y debilidades que imposibilitan el proceso de rescate de cultivos autóctonos en función del desarrollo comunitario.

Grupos focales: La aplicación de éste tipo de grupos constituyó favorablemente al cumplimiento metodológico y a los objetivos del trabajo investigativo enfocada en el principio de autodesarrollo, esta técnica fue aplicada a los representantes o grupos de la comunidad, los cuales están al tanto de sus dificultades y que afectan el desarrollo del sector. Los grupos son: Tantanishpa Purina, Teresa de Calcuta, Rumiñahui, Kuri, Consejo Pastoral, Junta de Agua, Presidencia del Cabildo, Comité de Padres de Familia de la Escuela Lago de San Pablo y Consejo Académico del Colegio Agropecuario a Distancia "Nukanchik Kawsay". La elección de este método se debe a que se evitan las relaciones entre los integrantes de un mismo grupo.

En la presente investigación, el grupo focal se aplicó en los seis primeros talleres y estuvo conformado por nueve miembros y las sesiones no sobrepasaron la hora (excepto la primera reunión que duró más de una hora), además que los talleres se realizaron los días domingos desde la 15 h: 30 pm. En la Escuela Lago de San Pablo, debido que presta las condiciones favorables para el desarrollo de las actividades.

Para empezar las sesiones se comenzó con la presentación del equipo participante y el interventor, después se realizó el encuadre. En el encuadre se tomó en consideración la duración de cada taller, el objetivo, el propósito, la forma de pedir la palabra, se preguntó las expectativas que tienen de los talleres; esta técnica no sobrepaso la media hora de la sesión. Se explicó que para la consecución exitosa de esta actividad, es de vital importancia la colaboración sincera, formal y comprometida y se aclaró que el interventor no es el especialista en el tema, sino que lo relevante es la elaboración conjunta. Se aplicó la metodología del autodesarrollo comunitario, la cual consta de las siguientes etapas:

Primera etapa: Intercambio inicial con el sujeto demandante de la acción profesional: La finalidad de esta etapa es conocer la percepción del sujeto demandante sobre sus características generales, los problemas que requieren solución priorizada y los escenarios particulares más afectados. Además de la formulación del sistema de contradicciones subyacentes a la problemática planteada por el demandante y finalmente acordar el plan inicial para la acción profesional. 
Se debe tomar en cuenta que el profesional tenga claro la diferencia entre demanda y necesidad, debido a que los sujetos por desconocimiento de las causas reales de sus malestares explican demandas que encubren los elementos esenciales que motivan su malestar; es por ello que, el momento de la hipotetización de la demanda es muy relevante en el proceso porque contribuye desde el inicio del trabajo social a la potenciación de la conciencia crítica del demandante sobre las causas reales de su demanda.

Segunda Etapa: Exploración del escenario o un pre-diagnóstico: En esta etapa se capta los datos empíricos relacionados con la problemática del demandante y confrontarlos con la problemática del demandante y confrontarlos con la demanda formulada que permita contar con los elementos que ayuden a organizar y planificar las etapas posteriores de la intervención. Los datos empíricos se recolectan mediante el análisis de documentos, la observación del participante, las entrevistas individuales y la utilización de encuestas. Con esta información permite al profesional construir los indicadores teóricos con los que según su apreciación se organizará la propuesta metodológica de intervención, de la cual se deriva la matriz para el diagnóstico participativo, que posteriormente la detallaremos.

Tercera Etapa: Diagnóstico y búsqueda de soluciones comunitarias: Es importante porque permite realizar el diagnóstico de la problemática a resolver por parte del demandante y facilitar el proceso corrector. Esto ocurre a través de diferentes vías, pero especialmente, a través de espacios grupales de reflexión. Si desde otros referentes metodológicos, los programas de intervención se organizan, emergen, como resultado de la confrontación que hace el profesional de los datos empíricos obtenidos y los referentes teóricos de partida, lo repercute favorablemente sobre las áreas que necesitan ser objeto de intervención, desde la metodología, la elaboración de los indicadores teóricos para la intervención es acompañada por la construcción de los indicadores diagnósticos de población; es decir, las características del modo de vida relacionados con el problema demandado, sobre los cuales esta no reflexiona y por tanto no se hace cuestionamientos, lo que se logra a través de técnicas y procedimientos descritos anteriormente con la utilización del grupo reflexivo.

Como resultado de esta etapa es que, se potencia la autonomía, la inteligencia, el protagonismo y la participación real del demandante en la superación de las contradicciones propias y de su entorno. Una vez explicadas las tres etapas, en la presente investigación se identificaron las siguientes variables e indicadores:

Variable dependiente: Rescate de los cultivos autóctonos

Variable independiente: Programa de intervención comunitaria

Indicadores:

- Conocimiento de las especies nativas

- Conocimiento de las propiedades medicinales y nutricionales de los cultivos autóctonos

- Conocimiento de técnicas de manejo y procesamiento de cultivos autóctonos

- Presencia de apoyo institucional

- Conciencia crítica

- Cooperación

- Participación. 
Grupo de reflexión: También se lo denomina Grupo Operativo en ese sentido ha apuntado a la resolución de los objetivos propuestos por el grupo y su tarea consiste en el develamiento de lo latente en tanto obstáculo para el pensar, el aprendizaje y la transformación. Los obstáculos serían una expresión de las resistencias al cambio, lo cual expresaría la presencia de ansiedades básicas como el miedo a la pérdida y el miedo al ataque., esbozándose así en definitiva los antecedentes básicos de los Grupos de Reflexión. La aplicación de éste tipo de grupos constituyó favorablemente al cumplimiento metodológico y a los objetivos del trabajo investigativo enfocado en el principio de autodesarrollo, esta técnica fue aplicada a los representantes de la comunidad, los cuales están al tanto de sus dificultades y que afectan el desarrollo del sector.

En la presente investigación, el grupo de reflexión estuvo conformado por 22 miembros entre representantes de la comunidad e informantes claves y las sesiones sobrepasaron la hora, fue muy importante considerar que las reuniones se realizaron los días domingos desde la $15 \mathrm{~h}$ : 30 pm. En la Escuela Lago de San Pablo, ya que, presta las condiciones favorables para el desarrollo de las actividades. Para empezar las sesiones se comenzó con la presentación del equipo participante y el interventor, después se realizó el encuadre. Esta técnica se aplicó en la tercera etapa; es decir, en el séptimo y octavo taller de trabajo.

Método de subsecciones etiquetados (Descripción de los participantes): Los participantes del proyecto pertenecen a la comunidad de Tuncarta (22 directos y 480 indirectos) del cantón Saraguro de la provincia de Loja. Las principales actividades están destinadas a la agricultura, ganadería con animales menores y pocos practican las artesanías en el sector.

Población y muestra: Para la población y muestra se consideró a moradores del sector de Tuncarta (tanto productores como consumidores), y organismos de apoyo social del cantón Saraguro, provincia de Loja. La muestra utilizada fue la probabilística estratificada, ya que, la selección se llevó a cabo en forma mecánica y objetiva, fueron procedimientos aleatorios en cada estrato; en este caso se investigó a productores, consumidores indígenas y mestizos del sector e instituciones que brindan ayuda social, ya sean hombres o mujeres (Abrigo,2016).

Los niveles de medición de las variables fueron primeramente identificadas como cualitativas nominales; las cuales estuvieron representadas por categorías y, sus elementos se identificaron como cualidades o atributos que no se midieron numéricamente. En este caso las categorías de las variables no tuvieron orden jerárquico. Las encuestas facilitaron la recolección de información suficiente a fin de verificar los objetivos planteados y la hipótesis; las cuales se analizaron e interpretaron por la muestra seleccionada.

Estas encuestas y entrevistas facilitaron la recolección de la información, la cual fue suficiente para verificar los objetivos planteados y la hipótesis; las cuales fueron analizadas e interpretadas por la muestra seleccionada.

Codificación de datos y tabulación: Una vez realizada la encuesta se codificaron los datos de cada variable, para ello le asignamos valores numéricos a las categorías. Esta codificación se la hizo cuantitativamente mediante la aplicación de un análisis estadístico. El tipo 
de tabulación aplicada fue la simple y la aplicada, donde encontramos las frecuencias de las diferentes categorías para el número total de observaciones que fueron de tipo cualitativo y cuantitativo; para lo cual utilizamos tablas. A continuación, aplicamos la estadística descriptiva para los datos, utilizando un programa estadístico. Con los resultados obtenidos del proceso de intervención, se valoró el proyecto de autodesarrollo comunitario, conjuntamente con las personas involucradas en esta formación.

Procedimientos: En el aspecto teórico se abarcará conceptos fundamentales referentes al tema, basándose en la utilización de bibliografía que pueda existir sobre la investigación que guíen al proponente a la construcción del proyecto de intervención comunitaria. Finalmente con los resultados obtenidos se elaboraran las conclusiones y recomendaciones que se espera que sean tomadas en cuenta por los interesados en el tema y comunidad en general.

Diseño de la investigación: El diseño de la investigación fue cualitativa, refiriéndose a la recopilación de información en función de las técnicas ya establecidas. Luego, la información obtenida fue analizada de una manera interpretativa, subjetiva, impresionista o incluso diagnóstica (Calero, 2000).

Características de los participantes: La participación de los moradores de la comunidad de Tuncarta fue fundamental para la realización de la investigación; ya que, sus conocimientos y sabiduría sirvió como referentes teóricos para completar la información; además fueron participes de los talleres.

Matriz del diagnóstico participativo: Se la utiliza para identificar los principales malestares de la comunidad de Tuncarta y para darles solución. Es un conjunto de técnicas y herramientas que permite que las comunidades hagan su propio diagnóstico y de ahí comiencen a auto-gestionar su planificación y desarrollo. De esta manera, los participantes podrán compartir experiencias y analizar sus conocimientos, a fin de mejorar sus habilidades de planificación y acción. (Abrigo, 2012) Aunque originariamente fue concebido para zonas rurales, muchas de las técnicas del DDP se pueden utilizar igualmente en comunidades urbanas (Verdejo, 2003).

\section{Resultados}

Diagnosticar el estado actual de la producción de los cultivos autóctonos:

Primera etapa: Intercambio inicial con el sujeto demandante de la acción profesional: Esta actividad se desarrolló con el antiguo directorio del Cabildo, en el mes de noviembre del 2011.

Fue la primera aproximación con los sujetos necesitados, para ello se desarrolló un intercambio con los líderes del Cabildo de Tuncarta, que son: el presidente, vicepresidente, secretario, tesorero, síndico y mayorales; los cuales brindaron su confianza y pudieron dar a conocer sus debilidades, requiriendo de ayuda profesional y orientación, implicando así de manera positiva hacia nuestro propósito investigativo. Dieron a conocer los aspectos socio organizativos de la comunidad, como por ejemplo organización social, actividades culturales, actividades productivas, entre otras. 
Segunda etapa: exploración del escenario y pre diagnóstico: Para la elaboración de ésta etapa, se aplicaron métodos citados con anterioridad, cuyos resultados los explicamos a continuación:

\section{Primer Taller de Trabajo}

Propósito: “Construir de manera conjunta una definición de rescate de cultivos autóctonos".

Desarrollo de la actividad: Inmediatamente de haber explicado en el encuadre, las actividades a realizar en el evento, se lanzó la pregunta ¿que entienden por rescate de cultivos autóctonos?, la respuesta fue inmediata, por parte de la Presidenta del Consejo Pastoral, luego el Presidente del Grupo Rumiñahui, posteriormente el Presidente del Grupo Kuri y finalmente el Presidente de la Junta de Agua; también se hizo énfasis en situaciones que ellos habían experimentado, en donde hayan tenido ejemplos de rescate, es decir las actividades que han realizado en este sentido. Esta actividad se la desarrolló el domingo 15 de enero del 2012 a las 15 h: $30 \mathrm{pm}$, con siete representantes de la comunidad e informantes claves.

El rescate de los cultivos autóctonos, es la idea central a tratar por los participantes, ellos dieron respuestas muy concretas y sencillas, aunque un poco descoordinadas. Pero es importante destacar que la Presidenta del Consejo Pastoral tiene una visión más conceptualizada, en cuya intervención manifestaba que: “...el rescate de los cultivos autóctonos es, salvar los cultivos nuestros, los criollos que se los está haciendo perder y debemos volver a sembrar para recuperarlos...”Por otra parte el Presidente del Grupo Kuri expresa: “...las plantas nativas del lugar no necesitan fungicidas ni herbicidas y por lo tanto son muy nutritivas y saludables ..." y finalmente el presidente del Grupo Rumiñahi dice que: “...volver a sembrar las plantas que antes no las sembrábamos...".

En el transcurso de la reunión se empezaron a verter nuevas ideas por parte los de los participantes, donde manifiestan, el Presidente de la Junta de Agua que: “...el rescate no solamente se debe hacer en los cultivos autóctonos, sino que también será un rescate de la cultura, el idioma, la tradición, las costumbres de la comunidad a la que pertenecemos; hablando específicamente de vestimenta y de nuestra identidad que se está perdiendo cada día, lo importante sería rescatar nuestros propios valores como saraguros que somos..."Además nos manifestaron que no existe colaboración ni participación para rescatar los cultivos nativos por parte de los directorios del Cabildo.

Con estas versiones se llegó a un consenso de que el rescate de los cultivos autóctonos es construir lo que se está destruyendo, sembrar nuestras propias semillas, ya que esto implica a que nuestros antepasados sean personas con excelente salud, autóctono es lo nativo, lo nuestro, el arte, la música. Finalmente se definió que el rescate de los cultivos autóctonos como: "...Aplicación de técnicas de manejo para salvar las plantas nativas o andinas..."

Se observó que los resultados fueron muy beneficiosos para todos, existiendo bienestar en los participantes, se concretó la próxima sesión para el 22 de enero del 2012 a las 15: h 30 pm, 
donde cada uno de los participantes expondrán los principales conocimientos que poseen sobre las bondades medicinales que poseen los cultivos autóctonos, los cuáles serán tema de debate.

\section{Segundo Taller de Trabajo}

Propósito: "Construir de manera conjunta una definición sobre los conocimientos que poseen sobre las bondades medicinales de los cultivos autóctonos"

Desarrollo de la actividad: Inmediatamente de haber explicado en el encuadre, las actividades a realizar en el evento, se lanzó la pregunta ¿qué conocimientos posee usted sobre las bondades medicinales de los cultivos autóctonos?, la respuesta no fue inmediata, hubo un ambiente de tranquilidad y después empezaron a opinar. Esta actividad se la desarrolló el domingo 22 de enero del 2012 a las 15 h: 30 pm, con nueve representantes de la comunidad e informantes claves.

Los conocimientos sobre las bondades medicinales que los cultivos autóctonos poseen, fue la idea central a tratar por los participantes, ellos dieron respuestas muy concretas y sencillas. Manifestaron sobre las bondades medicinales y dijeron: La representante del Grupo Tantanishpa Purina en cuya intervención manifestaba que: “...existen otras plantas como el llantén que posee principios curativos, también la mashua ayuda a los problemas de próstata y la zanahoria blanca que se la prepara como jugo y sirve como una fuente importante de energía...." Por otra parte la Presidenta del Grupo Teresa de Calcuta expresa: “...el melloco se lo utiliza cuando se tiene dolores de cabeza o el cargazón por estar expuesto por demasiado tiempo al sol...." El presidente del Grupo Rumiñahi explica que, el trigo chancado sirve para la cangrena....” En cambio la representante del Colegio Agropecuario Nukanchik Kawsay dice que, el melloco se lo consume en grandes cantidades para aliviar problemas de gastritis...."

Se observó que los resultados fueron muy beneficiosos para todos, existiendo bienestar en los participantes, se concretó la próxima sesión para el 29 de enero a las 15: 30, donde cada uno de los participantes expondrán las bondades nutricionales de los cultivos autóctonos, los cuáles serán tema de debate.

\section{Tercer Taller de Trabajo}

Propósito: "Construir de manera conjunta una definición sobre los conocimientos que poseen sobre las bondades nutricionales de los cultivos autóctonos". Desarrollo de la actividad: Inmediatamente de haber explicado en el encuadre, las actividades a realizar en el evento, se lanzó la pregunta ¿qué conocimientos posee usted sobre las bondades nutricionales de los cultivos autóctonos?, la respuesta no fue inmediata, hubo un ambiente de tranquilidad y después empezaron a opinar. Esta actividad se desarrolló el día domingo 29 de enero del 2012 a las 15: h30, con 12 representantes de la comunidad e informantes claves.

Los participantes manifestaron lo siguiente: “....el presidente del Comité de Padres de Familia dice que: la oca es muy buena para la nutrición, la cual se ha venido consumiendo desde hace mucho tiempo y que actualmente se está perdiendo...." La representante del Colegio Agropecuario Ñukanchik Kawsay explica que, “....la mashua y la oca son alimentos muy 
importantes para los niños cuando están muy débiles, y cuando van a estudiar se les hace un preparado muy nutritivo; también manifiesta que la zanahoria blanca sirve para los niños para su vitalidad...." El presidente del Grupo Rumiñahi expresa que, “....no solamente es bueno el consumo de la oca y la mashua para los niños sino que, también lo es para los adultos por que, poseen vitaminas...."

Se observó que los resultados fueron muy beneficiosos para todos, existiendo bienestar en los participantes, se concretó la próxima sesión para el 05 de febrero a las 15: 30, donde cada uno de los participantes expondrá sobre los conocimientos que poseen sobre el procesamiento de los cultivos autóctonos, el cuál será tema de debate.

\section{Cuarto Taller de Trabajo}

Propósito: "Construir de manera conjunta una definición sobre los conocimientos que poseen sobre las formas de procesamiento de los cultivos autóctonos". Desarrollo de la actividad: Inmediatamente de haber explicado en el encuadre, las actividades a realizar en el evento, se lanzó la pregunta ¿qué conocimientos posee usted sobre el procesamiento de los cultivos autóctonos?. Los conocimientos sobre el procesamiento fue la idea central a tratar por los participantes, ellos dieron respuestas muy concretas y sencillas. Esta actividad se la efectuó el día domingo 05 de febrero del 2012 a las 15: h 30, con 12 representantes de la comunidad e informantes claves.

Para explicar el procesamiento primero participó la presidenta del Grupo Teresa de Calcuta explicando que “....del trigo se obtiene la machica y del melloco se elabora ensaladas y de la oca coladas...." El presidente del Comité de Padres de Familia en cambio expresa que, "....de la zanahoria blanca se elaboran tortillas...." El presidente del Grupo Rumiñahi dice que, "....algunas clases de melloco como el rojo redondo se utiliza para hacer dulces con azúcar, y el blanco largo en ensaladas...." Se observó que los resultados fueron muy beneficiosos para todos, existiendo bienestar en los participantes, se concretó la próxima sesión para el 12 de febrero a las 15: 30, donde cada uno de los participantes expondrá las principales causas que han originado el abandono de los cultivos autóctonos, los cuáles serán tema de debate.

\section{Quinto Taller de Trabajo}

Propósito: "Construir de manera conjunta las causas que han ocasionado el abandono de los cultivos autóctonos". Desarrollo de la actividad: Inmediatamente de haber explicado en el encuadre, las actividades a realizar en el evento, se lanzó la pregunta ¿cuáles son las causas que han originado el abandono de los cultivos autóctonos?, la respuesta no fue inmediata, hubo un ambiente de tranquilidad y después empezaron a opinar. Esta actividad fue realizada el 12 de febrero del 2012 a las 15: h30, con 15 representantes de la comunidad e informantes claves. Los conocimientos sobre las causas que han originado el abandono de los cultivos autóctonos, fue la idea central a tratar por los participantes, ellos dieron respuestas muy concretas y sencillas.

El representante del Grupo Kuri manifestaba que: “...las causas que han ocasionado el abandono de los cultivos autóctonos se debe a la falta de asesoramiento técnico por parte de los gobiernos sobre el manejo,...." Por otra parte la Presidenta del Consejo Pastoral expresa: “...que 
el abandono se debe a la competitividad que se da en los mercados con otros productos...." El presidente del Grupo Rumiñahui explica que: “...no se valora estos cultivos, no se cultiva y por ende la producción ha ido decayendo; es por ello que sentimos la necesidad de cultivarlos...." El presidente del Comité de Padres de Familia manifiesta que: “....la principal causa del abandono de los cultivos autóctonos se debe a la migración de los habitantes hacia otros lugares como Loja, Cuenca y parte del Oriente (Yacuambi) lo que ha implicado dejar de sembrar en estas tierras, y también por su sabor...." Otros participantes manifestaron lo siguiente: “....se ha dejado de sembrar por falta de abono orgánico, debido a que su utilización implica una mejora de la producción...." “....la estación invernal que ha soportado nuestro país, lo que hace que la semilla se pudra y los moradores no tengan interés por producir..." Otra persona manifiesta que se debe: “... al clima porque, está muy cambiante...” Nuevamente el presidente del Grupo Rumiñahui expresa que, “.... Se debe al desconocimiento de variedades con alto rendimiento, así como sus bondades medicinales, nutricionales y las formas del procesarlos, y a la aculturación...."

Otro colaborador manifiesta que "....las causas del abandono de los cultivos autóctonos, se debe al ciclo largo del cultivo, lo que lo hace poco competitivo ante otros productos y tengamos que elegir otros cultivos...." En su segunda intervención el presidente del Comité de Padres de Familia expresa que, “.... se debe a la falta de conocimiento técnico sobre el manejo de los cultivos..." Se observó que los resultados fueron muy beneficiosos para todos, existiendo bienestar en los participantes, se concretó la próxima sesión para el 19 de febrero a las 15: 30, donde cada uno de los participantes expondrá las principales consecuencias que han originado el abandono de los cultivos autóctonos, los cuáles serán tema de debate.

\section{Sexto Taller de Trabajo}

Propósito: "Construir de manera conjunta las consecuencias que han ocasionado el abandono de los cultivos autóctonos". Desarrollo de la actividad: Inmediatamente de haber explicado en el encuadre, las actividades a realizar en el evento, se lanzó la pregunta ¿cuáles son las consecuencias que han originado el abandono de los cultivos autóctonos?, la respuesta no fue inmediata, hubo un ambiente de tranquilidad y después empezaron a opinar. Esta actividad se efectuó el día domingo 19 de febrero del 2012 a las 15: h30, con 18 representantes de la comunidad e informantes claves. Los conocimientos sobre las consecuencias que han originado el abandono de los cultivos autóctonos, fue la idea central a tratar por los participantes, ellos no dieron respuestas inmediatas, se tuvo que enfatizar con ejemplos de otro tipo, en los cuales amerite causas y efectos, de esta manera se logró que los participantes pudieran emitir comentarios muy concretos y sencillos.

Un participante de la comunidad manifestaba que: “...las consecuencias por abandonar o no sembrar los cultivos autóctonos son, que las especies se encuentran en peligro de extinción y que sufrirán en el pasar del tiempo...." Por otra parte la Presidenta del Grupo Tantanishpa Purina expresa: “...que la consecuencia de no sembrar será que consumiremos productos fumigados y por tanto nos enfermaremos....” El presidente del Grupo Rumiñahui explica que: “...si abandonamos estos cultivos deberemos posteriormente consumir otros productos llamados chatarra, concordando con la anterior participación...." El presidente del Comité de Padres de Familia manifiesta que: “....si no producimos, viviremos pocos años en comparación con 
nuestros antepasados...." Otro participante manifestó lo siguiente: “.... Si no sembramos como efecto será desconoceremos las formas de procesar estos cultivos, así como sus bondades medicinales y nutricionales...." Se observó que los resultados fueron muy beneficiosos para todos, existiendo bienestar en los participantes, se concretó la próxima sesión para el 26 de febrero a las 15: 30, donde cada uno de los participantes expondrán las principales soluciones que se pueden aplicar para rescatar los cultivos autóctonos y consecuentemente su siembra.

\section{Matriz para el Diagnóstico Participativo}

De los resultados obtenidos de las encuestas y entrevistas aplicadas permitió elaborar los indicadores del diagnóstico de la población, expresados en la tabla 1.

Tabla 1. Matriz para el diagnóstico participativo, Tuncarta, mayo del 2012.

\begin{tabular}{|c|c|c|c|c|c|c|}
\hline \multirow[t]{2}{*}{ Problemas } & \multirow[t]{2}{*}{ Prioridad $^{1}$} & Factores Condici & lantes & \multirow[t]{2}{*}{$\begin{array}{l}\text { Posibles } \\
\text { Acciones }\end{array}$} & \multirow[t]{2}{*}{ Recursos } & \multirow[t]{2}{*}{$\begin{array}{l}\text { Aportes de } \\
\text { la } \\
\text { comunida } \\
\text { d }\end{array}$} \\
\hline & & Causas $^{2}$ & Consecuencias $^{3}$ & & & \\
\hline $\begin{array}{l}\text { 1. La migración } \\
\text { 2. Falta de } \\
\text { alumbrado público } \\
\text { 3. Falta de relaciones } \\
\text { con las Instituciones } \\
\text { privadas y públicas } \\
\text { 4. Carencia de } \\
\text { relaciones entre las } \\
\text { dos instituciones } \\
\text { educativas existentes } \\
\text { en la comunidad } \\
\text { 5. Poca participación } \\
\text { por parte de los } \\
\text { comuneros en la } \\
\text { planificación de } \\
\text { actividades de la } \\
\text { comuna } \\
6 \text {. Vías de acceso en } \\
\text { malas condiciones } \\
\text { 7. No existen } \\
\text { cooperativas de } \\
\text { producción } \\
\text { 8. Falta de } \\
\text { cooperación por } \\
\text { parte de organismos } \\
\text { de desarrollo } \\
\text { 9. Pérdida de la } \\
\text { identidad y cultura }\end{array}$ & $\begin{array}{l}\text { 1. La } \\
\text { migración } \\
\text { 2. Falta de } \\
\text { cooperació } \\
\mathrm{n} \text { por parte } \\
\text { de } \\
\text { organismos } \\
\text { de } \\
\text { desarrollo } \\
\text { 3. Pérdida } \\
\text { de los } \\
\text { cultivos } \\
\text { autóctonos }\end{array}$ & $\begin{array}{l}\text { 1. Falta de } \\
\text { asesoramiento } \\
\text { técnico por parte } \\
\text { de las } \\
\text { instituciones } \\
\text { sobre el manejo } \\
\text { de los cultivos } \\
\text { autóctonos. } \\
\text { 2. } \\
\text { Desconocimiento } \\
\text { de las bondades } \\
\text { nutricionales, } \\
\text { medicinales y las } \\
\text { formas de } \\
\text { procesamiento de } \\
\text { los cultivos } \\
\text { autóctonos y del } \\
\text { manejo del } \\
\text { cultivos nativos } \\
\text { 3. Falta de } \\
\text { concientización y } \\
\text { desvalorización } \\
\text { de los cultivos } \\
\text { nativos } \\
\text { 4. Cambio de } \\
\text { lugar de trabajo } \\
\text { por sus tierras } \\
\text { infértiles }\end{array}$ & $\begin{array}{l}\text { 1. Abandono de } \\
\text { las tierras y } \\
\text { pérdida de } \\
\text { saberes } \\
\text { ancestrales } \\
\text { 2. Consumir } \\
\text { productos } \\
\text { fumigados y de } \\
\text { contextura } \\
\text { chatarra } \\
\text { 3. Propensos a } \\
\text { adquirir } \\
\text { enfermedades } \\
\text { 4. Importar } \\
\text { productos a } \\
\text { altos precios } \\
5 . \text { Extinción o } \\
\text { pérdida de los } \\
\text { cultivos } \\
\text { autóctonos } \\
6 . \\
\text { Desconocimient } \\
\text { o de las } \\
\text { bondades } \\
\text { medicinales y } \\
\text { nutricionales de } \\
\text { los cultivos. }\end{array}$ & $\begin{array}{l}\text { Para } \\
\text { controlar } \\
\text { parte de } \\
\text { los } \\
\text { problemas } \\
\text { y eliminar } \\
\text { los factores } \\
\text { condiciona } \\
\text { ntes, se } \\
\text { debe } \\
\text { analizar } \\
\text { problema } \\
\text { por } \\
\text { problema y } \\
\text { realizar } \\
\text { talleres de } \\
\text { capacitació } \\
\text { n y } \\
\text { conciencia } \\
\text { ción de las } \\
\text { consecuen } \\
\text { cias que } \\
\text { conducen } \\
\text { cada } \\
\text { problema } \\
\text { en orden } \\
\text { jerargico. }\end{array}$ & $\begin{array}{l}1 . \\
\text { Materiales } \\
\text {-Lápices, - } \\
\text { Computad } \\
\text { or -Infocus } \\
2 . \\
\text { Recursos } \\
\text { Humanos } \\
\text { Representa } \\
\text { nt } \\
\text { e del } \\
\text { Colegio } \\
\text { y de otros } \\
\text { organismo } \\
\text { s } \\
\text {-Aportes } \\
\text { económico } \\
\text { s } \\
\text { voluntarios } \\
\text {. }\end{array}$ & $\begin{array}{l}- \\
\text { Infraestruct } \\
\text { ura para } \\
\text { desarrollar } \\
\text { las sesiones } \\
\text {-Pequeñas } \\
\text { parcelas } \\
\text { para realiza } \\
\text { ensayos de } \\
\text { cultivos } \\
\text { nativos. El } \\
\text { responsable } \\
\text { de la } \\
\text { propuesta } \\
\text { se } \\
\text { encargará } \\
\text { de todas las } \\
\text { acciones } \\
\text { para lograr } \\
\text { los } \\
\text { objetivos } \\
\text { planteados. }\end{array}$ \\
\hline
\end{tabular}

\footnotetext{
${ }^{1}$ Hay que considerar que, a los problemas se los priorizo para resolver las necesidades de los comuneros y para cumplir con los objetivos de la investigación; es por ello que no se utilizó ningún tipo de ponderación.

${ }^{2}$ Son causas que han incididos en los problemas detectados como prioritarios

${ }^{3}$ Son consecuencias derivadas de las causas
} 


\begin{tabular}{ll}
\hline 10. Pérdida de los & 5. Largo ciclo del \\
cultivos autóctonos & cultivo \\
6. El temporal \\
invernal \\
7. Poca demanda \\
de los productos y \\
rentabilidad \\
8. Cambio de la \\
semilla en el \\
mercado \\
9. Introducción al \\
mercado de \\
productos no \\
tradicionales \\
\hline
\end{tabular}

En general se planteó que todo lo anterior podría ser concretado en la gestación de un proyecto de autodesarrollo comunitario que potencie el rescate de los cultivos autóctonos. Para lograr la consecución de la propuesta hemos visto necesario realizarlo en 15 días.

Tercera etapa: Proceso de diagnóstico y búsqueda de soluciones

\section{Séptimo Taller de Trabajo}

Propósito: "Construir de manera conjunta las soluciones que se pueden dar para rescatar los cultivos autóctonos"

Desarrollo de la actividad: Inmediatamente de haber explicado en el encuadre, las actividades a realizar en el evento, se lanzó la pregunta ¿cuáles son las soluciones que podemos dar para rescatar los cultivos autóctonos?, la respuesta no fue inmediata, hubo un ambiente de tranquilidad y después empezaron a opinar. Esta actividad se efectuó el día domingo 26 de febrero del 2012 a las 15: h30, con 18 representantes de la comunidad e informantes claves.

Los conocimientos sobre las soluciones para rescatar los cultivos autóctonos, fue la idea central a tratar por los participantes, ellos no dieron contestaciones inmediatas, se tuvo que esperar cierto tiempo para que ellos proporcionen respuestas muy concretos y sencillas.

La Presidenta del Grupo Tantanishpa Purina expresa: “...que la solución para rescatar los cultivos autóctonos sería, seguir impulsando éste tipo de proyectos para que en un tiempo no muy lejano se pueda recuperar esta sabiduría, y de esta forma poder ser competitivos y salir a vender al mercado....” El presidente del Grupo Kuri explica que: “... se debería poner en práctica lo aprendido en éstos talleres, y así poder difundir a toda la comunidad, especialmente a los más pequeños....” Otro participante manifiesta que: “.... Debemos hacer campañas o capacitaciones de concientización para sembrar estos cultivos y así no se pierdan....” La presidenta del Grupo Teresa de Calcuta manifestó lo siguiente: “.... Se debería empezar por rescatar las semillas nativas para posteriormente sembrar los cultivos..."

La presidenta del Consejo Pastoral manifiesta que, “...para rescatar éstos cultivos nativos debemos pedir asesoramiento técnico sobre el manejo del cultivo, así como sus formas de procesamiento, que por cierto se desconocen ..." Por otra parte manifiesta que, las instituciones 
deberían asesorarnos y facilitarnos el abono orgánico, lo que nos permitirá el rescate y la producción será más limpia sin químicos; en cambio un participante manifiesta que, "para rescatar los cultivos tradicionales deberíamos intercambiar las semillas con otras comunidades, ya que ellas poseen diferentes ecotipos. Se observó que los resultados fueron muy beneficiosos para todos, existiendo bienestar en todos los participantes, se concretó la próxima sesión para el 18 de marzo.

\section{Octavo Taller de Trabajo}

Propósito: "Lograr inducir en los moradores nuevas tecnologías para mejorar la producción y rescatar los cultivos autóctonos"

Desarrollo de la actividad: Inmediatamente de haber explicado en el encuadre, las actividades a realizar en el evento, se lanzó la pregunta ¿qué tecnología podremos aplicar para mejorar la producción en nuestros cultivos? ¿Sería aplicable en nuestra comunidad la tecnología empleada en las comunidades del norte, de acuerdo al video presentado?, ¿Cómo podremos relacionar con nuestro diario vivir el video sobre el trabajo en equipo?. La respuesta no fue inmediata, hubo un ambiente de tranquilidad y después empezaron a opinar. Esta actividad fue desarrollada el día domingo 18 de marzo del 2012 a las 15: h30, con 22 representantes de la comunidad e informantes claves.

E1 Presidente del Grupo Kuri expresa: “...que el video sobre el trabajo en equipo, es muy importante ya que nos permite concientizarnos y relacionarlos con nuestros problemas, y la solución para poderlos resolver sería que tenemos que unirnos y trabajar mancomunadamente....” El presidente del Cabildo explica que: “... se debería concientizar a los moradores de la comunidad e involucrarnos prácticamente todos para poder rescatar a éstos cultivos y lo importante sería trasmitir los conocimientos a las personas para que se vuelva a sembrar...." Otro participante manifiesta que: “.... Es importante para mejorar la producción sembrar los martes y jueves y lo que se debería hacer es experimentar y saber cuál es la producción; también se pudo apreciar que en luna llena no se puede sembrar y a lo mejor estamos sembrando cuando no es debido...." La presidenta del Tantanishpa Purina manifestó lo siguiente: “...Me llamó la atención del video que cuando sembramos no lo invocamos al ser supremo y a la madre tierra...."

La presidenta del Consejo Pastoral manifiesta que, “...nosotros tenemos algunas costumbres y tradiciones que no las valoramos, ósea no debemos sembrar, deshierbar ni podar en una tierna, porque la planta crece hermosa pero no produce, realmente es por lo que no ponemos atención ..." Por otra parte manifiesta que, en nuestro país se cultivan cerca de 50 variedades de oca, pero solamente se conocen tres: la amarilla, negra y blanca; lo importante sería investigar donde existen ese tipo de semillas ..."

El presidente del Grupo Rumiñahui expresa que, “... de acuerdo al video y al proceso de rescate de semillas andinas, tendrán que formar parte las universidades y centros de apoyo para elaborar parcelas demostrativas con los cultivos nativos y se realizaría un inventario de las semillas preguntando inicialmente a las personas de la tercera edad para saber si posee este material vegetal. También para saber una parte de los saberes ancestrales funciona todo 
articulado, es decir, la medicina, la alimentación y la espiritualidad, en conexión con el firmamento, con los cosmos..." Un participante manifiesta que, “...para mejorar la producción debemos inicialmente rescatar éstos cultivos y después aplicar tecnologías de mejora, para ello debemos concientizarnos y tener voluntad de trabajo, organizándonos y cooperando para resolver este problema..."

El presidente del Comité de Padres de Familia en cambio manifiesta que, “...debemos trasmitir a las futuras generaciones estas problemáticas para en un futuro no muy lejano podamos recuperar a los cultivos autóctonos..." La representante del Colegio Agropecuario Nukanchik Kawsay explica que, “...para rescatar los cultivos nativos y consecuentemente mejorar la producción se debería principalmente organizarnos en grupos para poder averiguar dónde se encuentra la semilla de éstos cultivos, y así poderla adquirir y darle el debido tratamiento; otro grupo se encargaría de la preparación de la tierra ..." Otro participante manifiesta que, “...la tecnología aplicada estará versada para aumentar la producción y dar a conocer las bondades medicinales, nutricionales y el valor agregado de éstos cultivos nativos se los obtendría mediante un procesamiento; la producción la aumentaríamos si preparamos la tierra de forma más eficiente y así obtendríamos un producto de mejor calidad. Además se debería incorporar estiércol de animales que se los obtendría de nuestras casas, como también los desperdicios de la cocina. Se observó que los resultados fueron muy beneficiosos para todos, existiendo bienestar en los participantes.

Luego de la experiencia obtenida por los participantes en el transcurso de los talleres, surgieron ideas muy valiosas para lograr la transformación en la comunidad de Tuncarta, quedando de acuerdo en la mayoría de todos, desarrollar una propuesta para potenciar el rescate de los cultivos autóctonos. Propuesta de intervención comunitaria para potenciar el rescate de los cultivos autóctonos en la comunidad de Tuncarta del cantón Saraguro:

Nombre del Proyecto: "Rescate de la tradición alimenticia ancestral de los habitantes de la comunidad de Tuncarta del cantón Saraguro provincia de Loja"

Localización: El proyecto de Desarrollo Comunitario que a continuación se expone pertenece al sector de Tuncarta, parroquia y cantón Saraguro y provincia de Loja; altitud 2850 msnm; con una temperatura media anual de $8^{\circ} \mathrm{C}$; precipitación anual media de $1100 \mathrm{~mm}$ y con una zona de vida bosque seco montano bajo (bs - MB), humedad relativa del $65 \%$, con aproximadamente 480 habitantes (Abrigo, 2016).

Población Meta: La población beneficiada de este proyecto serán moradores del sector de Tuncarta.

Justificación: Este proyecto se justifica a raíz del problema principal detectado a través de las tres etapas de intervención realizadas mediante los grupos focales, reflexión, entrevistas a profundidad y encuestas. Se ha observado una falta de concienciación, participación, motivación y cooperación por parte de toda la comunidad de Tuncarta, especialmente de los jóvenes. Se trata de realizar un programa de actividades que permita de alguna manera, lograr la conciencia crítica y la transformación en su modo de pensar, actuar y vivir, para rescatar y mejorar la producción 
de los cultivos autóctonos, que poco a poco están desapareciendo, lo cual lo lograremos mediante la participación de toda la comunidad.

Ámbito de Acción: El proyecto de Intervención Comunitaria se dirige a la siguiente población: Jóvenes mayores de 16 años: se formarán tres grupos de 5 jóvenes cada uno. Estos grupos facilitarán la participación de los jóvenes del sector. Se intentará que cada grupo tome iniciativas a la hora de realizar actividades, organizándose y cooperando en equipo. Personas mayores de 60 años: se formarán tres grupos de 5 personas cada uno. Estos grupos facilitarán la participación de las personas mayores de este territorio. Se intentará que cada grupo tome iniciativas a la hora de realizar actividades, organizándose y cooperando en equipo.

El objetivo de haber seleccionado a estas dos franjas de edad de la población es el de realizar un inventario y conseguir la semilla de los cultivos autóctonos; para promover y difundir posteriormente los resultados obtenidos en ellos a toda la comunidad, al que se invitará a participar en las actividades que vayan programando, lo que fomentará mayor comunicación y reforzará su identidad como tal.

\section{Recursos Humanos}

Grupo de Base: Docentes del colegio, trabajador social del sector y otros colaboradores.

Representante del Cabildo: Será designado por su titular.

Representante institucional: Será elegido de un Organismo privado o público existente en el cantón Saraguro.

\section{Materiales}

Instalaciones de la Escuela Lago de San Pablo perteneciente a la comunidad, casa Comunal. Material para los diferentes talleres entregados por la comunidad.

Enfoque Metodológico: Para alcanzar los objetivos propuestos, este proyecto será puesto en marcha por un Grupo de Base. Se deberá contar primero con las aulas de la Escuela Lago de San Pablo, además de la participación de los profesores y los habitantes del sector involucrado. Se contará con la colaboración de estas personas y de las instituciones para que fomenten la participación de la comunidad en las actividades que se desarrollarán en el proyecto.

Cada docente desde la escuela y colegio, también nos ayudará desde su aula a explicar el Proyecto de Intervención Comunitaria y la importancia de participar en el mismo. Además de esto, se anunciará el proyecto en la radio "EL Buen Pastor", incidiendo mucho en lo valioso de la participación comunitaria para poder rescatar los cultivos autóctonos para la atracción del sector y del cantón Saraguro.

El Grupo Base supervisará las actividades coordinadas por los participantes. La realización de las actividades propuestas en el proyecto debe ser principalmente: 
a) Participativas: involucrando a toda la comunidad de Tuncarta.

b) Flexibles: Las actividades podrán ser modificadas o adaptadas según decisiones de los mismos comuneros.

c) Motivadoras.

d) Coherentes con los objetivos.

\section{Objetivo General:}

Fomentar el rescate de los cultivos autóctonos y mejorar la producción en el sector de Tuncarta, promoviendo la participación e implicación de los ciudadanos en las actividades programadas para su realización.

\section{Objetivos Específicos:}

a) Desarrollar actividades de participación e implicación de la comunidad y de las Instituciones para conseguir mejorar el ambiente comunitario en función del rescate de los cultivos, para conseguir una mejor calidad de vida en el sector de Tuncarta.

b) Mitigar las principales causas que ocasionan el abandono de los cultivos autóctonos.

c) Determinar las principales bondades medicinales, nutricionales y las formas de procesamiento que poseen los cultivos autóctonos.

d) Difundir tecnología de punta para mejorar la producción de éstos cultivos nativos.

e) Evitar las consecuencias que producen el abandono de los cultivos autóctonos.

Descripción de Actividades: El Proyecto de Intervención Comunitaria constará de la realización de una serie de eventos, para los que se diseñarán actividades, que se mencionan en la tabla 2.

Tabla 2. Actividades a desarrollarse en el proyecto. Rescate de la tradición alimenticia ancestral de los habitantes de la comunidad de Tuncarta, mayo del 2012.

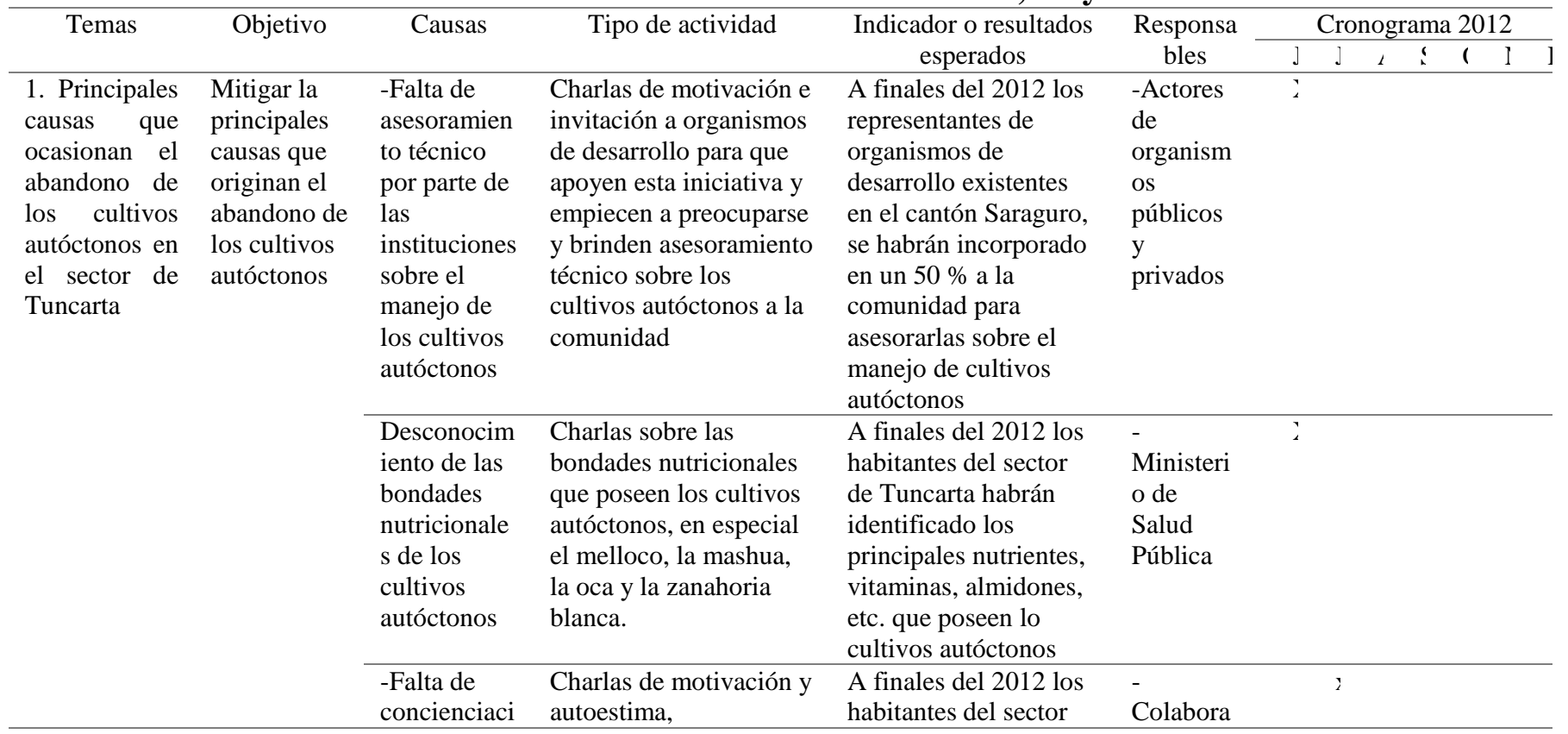




\begin{tabular}{|c|c|c|c|c|c|c|c|}
\hline & & $\begin{array}{l}\text { ón y } \\
\text { desvalorizac } \\
\text { ión de los } \\
\text { cultivos } \\
\text { nativos }\end{array}$ & $\begin{array}{l}\text { especialmente para los } \\
\text { jóvenes para valorar los } \\
\text { cultivos autóctonos en } \\
\text { la comunidad }\end{array}$ & $\begin{array}{l}\text { de Tuncarta los } \\
\text { jóvenes del sector se } \\
\text { habrán } \\
\text { motivado en un } 50 \% \\
\text { para manejar los } \\
\text { cultivos autóctonos; } \\
\text { así como habrán } \\
\text { aumentado su } \\
\text { autoestima para } \\
\text { valorar sus productos } \\
\text { en }\end{array}$ & $\begin{array}{l}\text { dores de } \\
\text { la } \\
\text { comunida } \\
\text { d } \\
- \\
\text { Colabora } \\
\text { dor social }\end{array}$ & & \\
\hline & & $\begin{array}{l}\text {-Cambio de } \\
\text { lugar de } \\
\text { trabajo por } \\
\text { sus tierras } \\
\text { infértiles }\end{array}$ & $\begin{array}{l}\text { Talleres de } \\
\text { concienciación para no } \\
\text { abandonar las tierras } \\
\text { existentes en el sector } \\
\text { de Tuncarta }\end{array}$ & $\begin{array}{l}\text { A finales del } 2012 \text { los } \\
\text { habitantes del sector } \\
\text { de Tuncarta habrán } \\
\text { aplicado nuevas } \\
\text { tecnologías para } \\
\text { mejorar la textura, } \\
\text { estructura y fertilidad } \\
\text { de sus suelos mediante } \\
\text { la aplicación de } \\
\text { abonos orgánicos y } \\
\text { consecuentemente no } \\
\text { migraran a otros sitios. }\end{array}$ & $\begin{array}{l}- \\
\text { Colabora } \\
\text { dores de } \\
\text { la } \\
\text { comunida } \\
\text { d }\end{array}$ & I & \\
\hline & & $\begin{array}{l}\text {-Largo ciclo } \\
\text { del cultivo }\end{array}$ & $\begin{array}{l}\text { Talleres sobre el } \\
\text { conocimiento de } \\
\text { variedades de cultivos } \\
\text { autóctonos que } \\
\text { presenten el ciclo } \\
\text { vegetativo corto }\end{array}$ & $\begin{array}{l}\text { A finales del } 2012 \text { los } \\
\text { habitantes del sector } \\
\text { de Tuncarta habrán } \\
\text { desarrollado un } \\
\text { inventario de las } \\
\text { semillas que presenten } \\
\text { su ciclo vegetativo } \\
\text { más corto que las } \\
\text { variedades existentes. }\end{array}$ & $\begin{array}{l}- \\
\text { Colabora } \\
\text { dores de } \\
\text { la } \\
\text { comunida } \\
\text { d }\end{array}$ & & i \\
\hline \multirow[t]{3}{*}{$\begin{array}{l}\text { 2. Principales } \\
\text { consecuencia } \\
\text { s que } \\
\text { ocasionan el } \\
\text { abandono de } \\
\text { los cultivos } \\
\text { autóctonos en } \\
\text { el sector de } \\
\text { Tuncarta }\end{array}$} & \multirow[t]{3}{*}{$\begin{array}{l}\text { Evitar las } \\
\text { principales } \\
\text { consecuenci } \\
\text { as que } \\
\text { originan el } \\
\text { abandono de } \\
\text { los cultivos } \\
\text { autóctonos }\end{array}$} & $\begin{array}{l}\text {-Abandono } \\
\text { de las tierras }\end{array}$ & $\begin{array}{l}\text { Talleres sobre } \\
\text { motivación y } \\
\text { concienciación para que } \\
\text { los moradores del sector } \\
\text { de Tuncarta, no } \\
\text { abandonen sus tierras }\end{array}$ & $\begin{array}{l}\text { A finales del } 2012 \text { los } \\
\text { habitantes del sector } \\
\text { de Tuncarta en un } 50 \\
\% \text { se habrán } \\
\text { concienciado para } \\
\text { producir los cultivos } \\
\text { autóctono y de esta } \\
\text { manera no abandonen } \\
\text { sus tierras }\end{array}$ & $\begin{array}{l}- \\
\text { Colabora } \\
\text { dores de } \\
\text { la } \\
\text { comunida } \\
\text { d }\end{array}$ & & i \\
\hline & & $\begin{array}{l}\text {-Pérdida de } \\
\text { saberes } \\
\text { ancestrales }\end{array}$ & $\begin{array}{l}\text { Talleres sobre } \\
\text { motivación y } \\
\text { concienciación para que } \\
\text { los moradores del sector } \\
\text { de Tuncarta recuperen } \\
\text { sus saberes ancestrales }\end{array}$ & $\begin{array}{l}\text { A finales del } 2012 \text { los } \\
\text { habitantes del sector } \\
\text { de Tuncarta en un } 50 \\
\% \text { se habrán } \\
\text { concienciado para } \\
\text { recuperar sus saberes } \\
\text { ancestrales }\end{array}$ & $\begin{array}{l}- \\
\text { Colabora } \\
\text { dores de } \\
\text { la } \\
\text { comunid }\end{array}$ & & 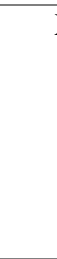 \\
\hline & & $\begin{array}{l}\text {-Consumir } \\
\text { productos } \\
\text { fumigados y }\end{array}$ & $\begin{array}{l}\text { Talleres sobre } \\
\text { motivación y } \\
\text { concienciación para que }\end{array}$ & $\begin{array}{l}\text { A finales del } 2012 \text { los } \\
\text { habitantes del sector } \\
\text { de Tuncarta en un } 50\end{array}$ & $\begin{array}{l}\text { - } \\
\text { Colabora } \\
\text { dores de }\end{array}$ & & 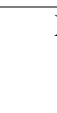 \\
\hline
\end{tabular}




\begin{tabular}{|c|c|c|c|c|c|c|}
\hline & & $\begin{array}{l}\text { de } \\
\text { contextura } \\
\text { chatarra }\end{array}$ & $\begin{array}{l}\text { los moradores del sector } \\
\text { de Tuncarta no } \\
\text { consuman alimentos } \\
\text { denominados chatarras }\end{array}$ & $\begin{array}{l}\text { \% se habrán } \\
\text { concienciado para no } \\
\text { consumir alimentos } \\
\text { denominados chatarras }\end{array}$ & $\begin{array}{l}\text { la } \\
\text { comunida } \\
\mathrm{d} \\
- \\
\text { Delegado } \\
\text { del MIES }\end{array}$ & \\
\hline & & $\begin{array}{l}\text {-Propensos } \\
\text { a adquirir } \\
\text { enfermedad } \\
\text { es }\end{array}$ & $\begin{array}{l}\text { Talleres sobre } \\
\text { motivación y } \\
\text { concienciación para que } \\
\text { los moradores del sector } \\
\text { de Tuncarta sepan a qué } \\
\text { enfermedades son } \\
\text { propensos }\end{array}$ & $\begin{array}{l}\text { A finales del } 2012 \text { los } \\
\text { habitantes del sector } \\
\text { de Tuncarta en un } 50 \\
\% \text { se habrán } \\
\text { concienciado para } \\
\text { conocer a que } \\
\text { enfermedades son } \\
\text { propensos al no } \\
\text { consumir cultivos } \\
\text { autóctonos }\end{array}$ & $\begin{array}{l}\text { - } \\
\text { Colabora } \\
\text { dores de } \\
\text { la } \\
\text { comunida } \\
\text { d } \\
\text { Delegado } \\
\text { del MSP }\end{array}$ & $i$ \\
\hline & & $\begin{array}{l}\text { - } \\
\text { Desconocim } \\
\text { iento de las } \\
\text { bondades } \\
\text { medicinales, } \\
\text { nutricionale } \\
\text { s y las } \\
\text { formas de } \\
\text { procesamien } \\
\text { to de los } \\
\text { cultivos }\end{array}$ & $\begin{array}{l}\text { Talleres sobre } \\
\text { motivación y } \\
\text { concienciación para que } \\
\text { los moradores del sector } \\
\text { de Tuncarta no } \\
\text { desconozcan sobre las } \\
\text { bondades de los cultivos } \\
\text { autóctonos }\end{array}$ & $\begin{array}{l}\text { A mediados del } 2013 \\
\text { los habitantes del } \\
\text { sector de Tuncarta en } \\
\text { un } 100 \% \text { se habrán } \\
\text { concienciado para } \\
\text { evitar que se } \\
\text { desconozcan las } \\
\text { bondades de los } \\
\text { cultivos }\end{array}$ & $\begin{array}{l}\text { - } \\
\text { Colabora } \\
\text { dores de } \\
\text { la } \\
\text { comunida } \\
\text { d }\end{array}$ & i \\
\hline \multirow{2}{*}{$\begin{array}{l}\text { 3. Prevención } \\
\text { de los } \\
\text { problemas } \\
\text { que afectan y } \\
\text { producen el } \\
\text { abandono de } \\
\text { los cultivos } \\
\text { autóctonos en } \\
\text { el sector de } \\
\text { Tuncarta }\end{array}$} & \multirow{2}{*}{$\begin{array}{l}\text { Determinar } \\
\text { las acciones } \\
\text { que } \\
\text { debemos } \\
\text { emprender } \\
\text { para } \\
\text { prevenir el } \\
\text { abandono } \\
\text { de los } \\
\text { cultivos } \\
\text { autóctonos }\end{array}$} & $\begin{array}{l}\text {-Abandono } \\
\text { de las tierras }\end{array}$ & $\begin{array}{l}\text { Talleres sobre } \\
\text { motivación y } \\
\text { concienciación para que } \\
\text { los moradores del sector } \\
\text { de Tuncarta, no } \\
\text { abandonen sus tierras }\end{array}$ & $\begin{array}{l}\text { A mediados del } 2013 \\
\text { los habitantes del } \\
\text { sector de Tuncarta en } \\
\text { un } 100 \% \text { se habrán } \\
\text { concienciado para } \\
\text { producir los cultivos } \\
\text { autóctonos y de esta } \\
\text { manera no abandonen } \\
\text { sus tierras }\end{array}$ & $\begin{array}{l}\text { - } \\
\text { Colabora } \\
\text { dores de } \\
\text { la } \\
\text { comunida } \\
\text { d }\end{array}$ & 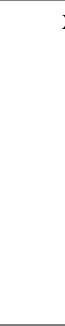 \\
\hline & & $\begin{array}{l}\text { - } \\
\text { Introducció } \\
\mathrm{n} \text { al } \\
\text { mercado de } \\
\text { productos } \\
\text { no } \\
\text { tradicionale } \\
\mathrm{s}\end{array}$ & $\begin{array}{l}\text { Talleres sobre } \\
\text { motivación y } \\
\text { concienciación sobre el } \\
\text { consumo de productos } \\
\text { tradicionales o nativos }\end{array}$ & $\begin{array}{l}\text { A mediados del } 2013 \\
\text { los habitantes del } \\
\text { sector de Tuncarta en } \\
\text { un } 100 \% \text { se habrán } \\
\text { concienciado para } \\
\text { consumir productos } \\
\text { nativos y no permitirán } \\
\text { la introducción de } \\
\text { cultivos no } \\
\text { tradicionales al } \\
\text { mercado }\end{array}$ & $\begin{array}{l}\text { - } \\
\text { Colabora } \\
\text { dores de } \\
\text { la } \\
\text { comunida } \\
\text { d } \\
\text {-MIES }\end{array}$ & 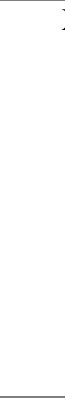 \\
\hline
\end{tabular}




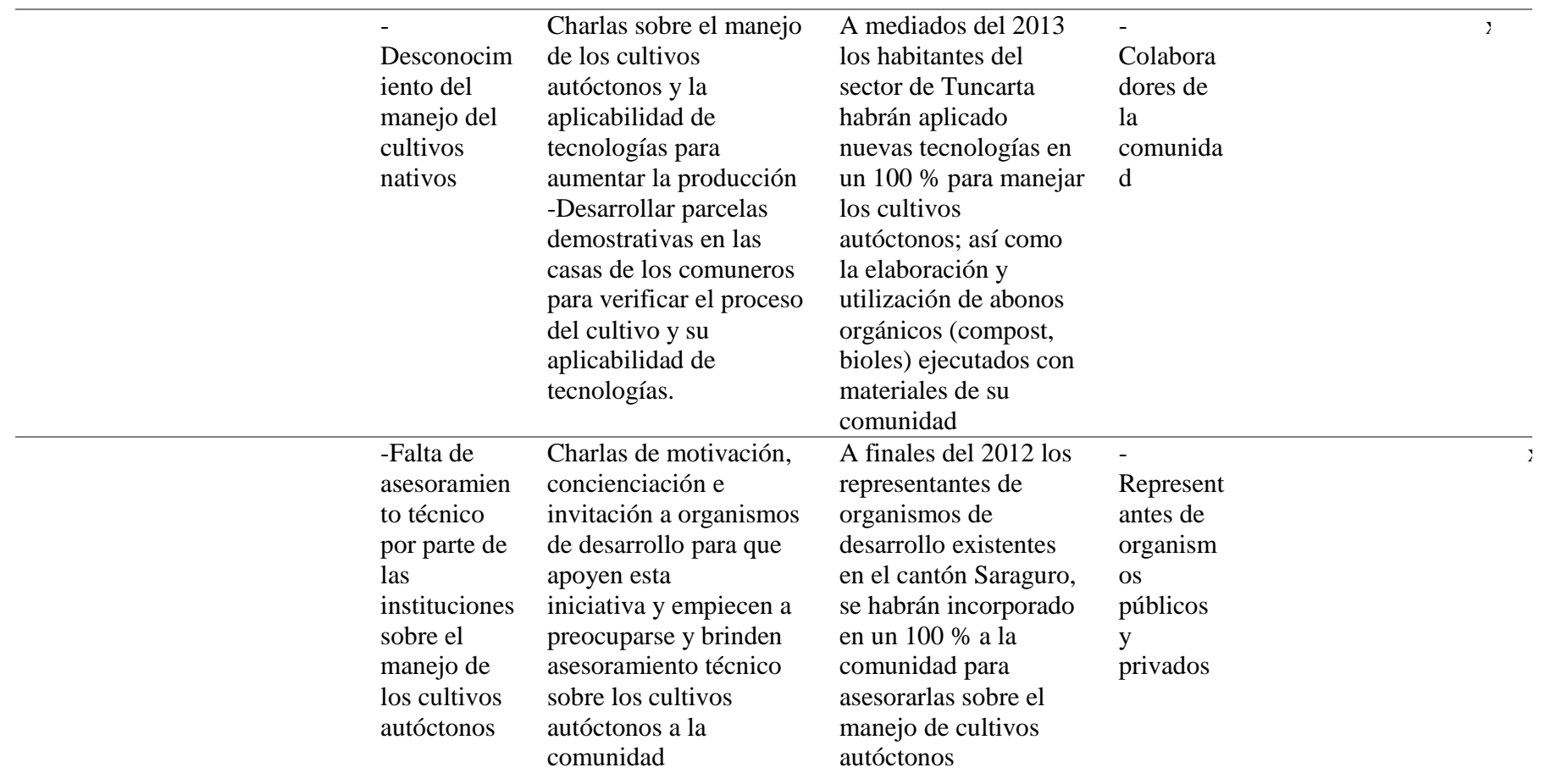

Evaluación y Propuesta para el Futuro: Al terminar los talleres, se hará una puesta en común y se evaluarán todas las actividades, analizando si han sido positivas. Se recogerán sugerencias de la comunidad que pueden llevar a mejorar las diferentes actividades, de este modo también motivaremos a los comuneros a participar y expresar sus opiniones.

El Grupo de Base conformado, también realizará una evaluación general del Proyecto, de las actividades realizadas y del funcionamiento de los talleres para poder observar si se han cumplido los objetivos, tanto los generales como los específicos y, en su caso, mejorar lo que proceda.

\section{Discusión}

El enfoque aplicado en la investigación fue el mixto; es decir, se refiere a la metodología cualitativa que se empleó, representando al tamaño muestral necesario en función de encuestas, observaciones y entrevistas aplicadas; las cuales describieron la cotidianidad, aspectos socioculturales, situaciones problemáticas y los significados de la vida de las personas de la comunidad de Tuncarta.

La utilización de esta metodología permitió mayor profundización en este estudio, ya que, penetró en la subjetividad de los implicados, los motivó el tema a debatir y los hizo mantener una actitud más crítica de su situación actual. Además reflexionaron en torno a los mecanismos para superar la actual problemática y proyectarse a optimizar la calidad de vida y por ende un mejor porvenir. Se utilizó la metodología del autodesarrollo para llevar a cabo el proceso de 
intervención comunitaria, en donde los resultados sirvieron para gestar el proyecto de autodesarrollo dirigido a potenciar el rescate de los cultivos autóctonos en la comunidad de Tuncarta.

\section{Primera etapa: intercambio inicial con el sujeto demandante de la acción profesional}

Esta primera etapa permitió determinar que uno de los principales problemas que afectan al sector es la migración, que se da por motivo de trabajo; es decir, en el sector no hay las fuentes necesarias para satisfacer esta necesidad, lo que ha implicado en la perdida de la identidad y su cultura, debido principalmente a la aculturación. Además el sector carece de alumbrado público. En lo que respecta a las relaciones se dan principalmente con organizaciones públicas, las cuales han apoyado con infraestructura, pero en lo que tiene que ver con asesoramiento técnico, especialmente en manejo de cultivos no se ve ese apoyo institucional, siendo las relaciones, en este ámbito nulas. La producción en el sector es agrícola, ganadera y artesanal en orden de importancia, la mayoría posee tierras con título de propiedad, con un promedio de una hectárea cada familia.

Los cultivos producidos son de ciclo corto y la crianza de animales es menores, los cuales son destinados para el autoconsumo, para ofrendar y para la venta, de los cuales se basan sus ingresos, que son cómodos, para solventar sus necesidades. Hay que destacar que no existe apoyo gubernamental y no gubernamental para el manejo de estas dos unidades de producción, debido a que su apoyo es principalmente para la infraestructura.

Hay que recalcar que para el manejo de los cultivos de la zona, existe un canal de riego y que las labores o actividades preculturales y culturales las desarrollan todos los miembros de la familia, existiendo una equidad de género.

Existe una escuela, en cuyas instalaciones funciona también un colegio a distancia, los maestros de las dos instituciones no se involucran en el desarrollo comunitario confinándose únicamente a sus labores académicas. Hay que considerar que, en la zona de aplica la justicia comunitaria, la cual permite sancionar las conductas equívocas de las personas, se desarrolla mediante reuniones establecidas todos los días domingos a partir de la 19: 00 pm., siempre y cuando amerite la situación de juzgamiento; también en esta dependencia se planifican las acciones comunitarias en beneficio de sus comuneros.

Todos los comentarios expuestos por los asistentes a éste evento pusieron en evidencia los problemas de falta de participación por parte de los comuneros y cooperación por parte de los organismos de desarrollo, ya sean gubernamentales y no gubernamentales, en lo que tiene que ver con el asesoramiento técnico de manejo de cultivos autóctonos lo que consecuentemente propician su abandono, debido al queme importismo y al desconocimiento de estos cultivos, así como su manejo y formas de procesamiento.

Como conclusión de ésta etapa quedo expresada la demanda comunitaria a favor de ejecutar un proyecto encaminado a potenciar el rescate de los cultivos autóctonos en la comunidad de Tuncarta. 


\section{Segunda etapa: exploración del escenario y pre diagnóstico}

Con la finalidad de diferenciar la demanda comunitaria con los datos empíricos a obtener a través de la exploración de la realidad aplicando para la recopilación de datos métodos ya descritos con anterioridad, en esta etapa se identificaron los siguientes problemas.

Hay que desatacar que los comuneros no cuentan con los conocimientos necesarios sobre las bondades nutricionales, medicinales y las formas de procesamiento y es motivo de preocupación, lo que se requiere es que exista la concientización y por ende la conciencia crítica de los habitantes del sector de Tuncarta para recuperar la sabiduría ancestral que se está perdiendo poco a poco. Esto se debe principalmente a la falta de asesoramiento por parte de los organismos de desarrollo, así como a la desvaloración de los habitantes sobré estas bondades.

Por otra parte el abandono de los cultivos autóctonos se debe principalmente: a la falta de asesoramiento técnico por parte de las instituciones sobre el manejo de los cultivos; inexperiencia sobre el manejo del cultivos nativos; falta de concientización y desvalorización de los cultivos nativos; cambio de lugar de trabajo por sus tierras infértiles; largo ciclo del cultivo; el temporal invernal; falta de abono orgánico; competitividad en el mercado con otros cultivos y el desconocimiento de variedades con alto rendimiento.

Es por ello que existe un fiel compromiso para seguir con este proceso de intervención, lo que se requiere es que exista la concienciación y por ende la conciencia crítica de los habitantes del sector de Tuncarta para mitigar estas causas y recuperar los cultivos nativos y por ende su sabiduría ancestral que se está perdiendo poco a poco.

Las consecuencias o efectos que han originado el abandono de los cultivos nativos estará versado en: los cultivos autóctonos se encontrarán en peligro de extinción y llegarán a desaparecer, lo que implica a que consumiremos productos fumigados o de contextura chatarra que nos harán daño a nuestra salud y finalmente no viviremos mucho tiempo. Otra consecuencia sería que si no se produce los cultivos autóctonos se desconocerá las formas de procesamiento; así como, sus bondades medicinales y nutricionales.

De acuerdo al análisis obtenido de las encuestas aplicadas a los consumidores deducimos que la mayoría de los habitantes consume cultivos autóctonos y que los tubérculos los obtienen de otras plazas, lo que implica un serio problema a resolver. Igualmente no cuentan con los conocimientos necesarios sobre las bondades medicinales, alimenticias y las formas de procesamiento.

En lo que respecta a las encuestas aplicadas a los productores, se observa que, no les han proporcionado el asesoramiento técnico para el manejo de los cultivos autóctonos, lo que implica el abandono total de este tipo de cultivos, lo ideal sería trabajar en técnicas de manejo para mejorar la producción y rescatar esta sabiduría. La tecnología aplicada para la producción de cultivos autóctonos en la comunidad de Tuncarta tiene mucho que decir; porque desde su inicio aplicaban técnicas, que inciden en la baja producción y rentabilidad al momento de obtener réditos económicos, llegando finalmente a desaparecer sus cultivos; para ello, sería necesario 
cambiar de mentalidad de las personas induciéndoles a sembrar y aplicar nuevas tecnologías mediante procesos de intervención comunitaria, que estén al alcance de sus posibilidades.

De acuerdo a Suquilanda, 2003, para poder aumentar la producción aplicando nuevas tecnologías sería, incorporando nutrientes al suelo, mediante la elaboración de abonos orgánicos como el compost, los cuales tienen como propósito producir alimentos de calidad natural conservando su equilibrio, no utilizando los productos químicos como los fertilizantes, satisfaciendo de esta manera las necesidades materiales como espirituales del comunero. No solamente mejoraría la fertilidad del suelo sino que también su textura, ya que el suelo de la zona intervenida es arcilloso.

Las razones por las que los productores del sector de Tuncarta no producen cultivos autóctonos se deben a la falta tecnología y apoyo institucional para manejar técnicamente los cultivos nativos. Por otra parte, la migración, largo ciclo del cultivo y las tierras infértiles y por qué las familias no valoran el aporte cultural ni el aporte nutricional inciden. Esta situación preocupa, ya que, son causas que han originado el abandono de los cultivos autóctonos, lo importante sería cambiar la mentalidad de los moradores y lograr en ellos una conciencia crítica para llegar a rescatar estos cultivos aborígenes. Mediante la encuesta aplicada a los representantes de Instituciones Públicas y Privadas nos manifiestan que, brindan cooperación a las comunidades del cantón Saraguro mediante la ejecución de proyectos productivos, de turismo, capacitaciones y fortalecimiento organizativo y social. En cambio el asesoramiento técnico sobre el manejo de los cultivos autóctonos no lo realizan, sin embargo ellos expresan que si tienen conocimiento sobre la pérdida de éstos cultivos.

Las causas de la pérdida según este sector importante de encuestados, se debe a que las especies han sufrido un proceso de aculturación y cambios en la dieta alimenticia, desconocimiento de las bondades medicinales y nutricionales, pérdida de los valores ancestrales y a la migración. Hay que recalcar que un porcentaje menor enfatiza que se debe a la falta de apoyo institucional, siendo algo contradictorio porque, en los coloquios anteriores se concluye que las instituciones no prestan asesoramiento técnico sobre el manejo de los cultivos nativos. Lo que se debería hacer primero es desarrollar talleres de concienciación para que estos organismos se involucren en este proceso y colaboren en este tema.

Por otra parte las alternativas de solución que expresan los encuestados para rescatar los cultivos autóctonos sería capacitar a las comunidades sobre el manejo incentivando a la gente para valorar estos productos, concienciando sobre sus bondades medicinales, nutricionales, así como, la preparación de platos típicos en donde existan degustaciones y se aprecien los cultivos nativos.

Percibiendo la problemática de manera general, es necesario desarrollar un proceso de intervención para concientizar a la gente para que participe y coopere, y así poder aplicar tecnología y mejorar la producción de este tipo de cultivos, de esta manera se rescataría estas especies y consecuentemente mejorarían su calidad de vida de los habitantes del sector. La alternativa para rescatar estos cultivos sería, dar importancia a los saberes ancestrales y desarrollar un programa de recolecta de semilla de cultivos andinos y así tratar de distribuir a la gente campesina del sector de Tuncarta. Se empezaría a desarrollar un inventario de las semillas 
existentes en la localidad para así distribuirlas a todos los campesinos y que empiecen a cultivarlas.

\section{Tercera etapa: diagnóstico y búsqueda de soluciones}

Esta etapa se refiere a las soluciones para rescatar los cultivos nativos y estará versado en: seguir impulsando este tipo de proyectos y poner en práctica lo aprendido en los talleres y así difundir a la comunidad y a los pequeños, para que de esta manera se pueda recuperar la sabiduría y así poder ser más competitivos; también desarrollar campañas de concientización para sembrar los cultivos y que no se pierdan, realizando primero un intercambio de semillas con otras comunidades. También sería importante que las instituciones se involucren y apoyen esta iniciativa con la colaboración de estiércol de animales para la consecuente elaboración de abonos orgánicos para mejorar la producción en el sector, así como el asesoramiento sobre el manejo de los cultivos nativos, sus bondades y formas de procesamiento que se desconocen.

Hay que desatacar que existe un fiel compromiso para seguir con este proceso de intervención, lo que se requiere es que exista la concienciación y por ende la conciencia crítica de los habitantes del sector de Tuncarta para recuperar los cultivos en la comunidad.

Con la presentación de los dos videos se logró mayor participación y cooperación en los asistentes y pudieron relacionarlos con los problemas que se encuentran inmersos en su comunidad, también se pudo evidenciar que en la zona de Chimborazo la tecnología aplicada da resultados al momento de manejar los cultivos autóctonos, siendo muy importante relacionarla con nuestra tecnología para aumentar la producción y por ende lograr el rescate definitivo. Luego de la ponencia, de tomar las propias decisiones para bien de la comunidad y poder realizar el autodesarrollo comunitario y realizar las debidas reflexiones se analizó los problemas priorizados que ocasionan el abandono de los cultivos, los cuales forman parte de la propuesta de intervención para potenciar en sí, el rescate de los cultivos nativos en el sector de Tuncarta.

Hay que desatacar que existe un fiel compromiso para seguir con este proceso de intervención, porque la unión, el compañerismo, la participación y cooperando todos lograremos la transformación en el sector de Tuncarta.

Esta propuesta es la consecuencia de la gestación de lo comunitario, que se consiguió a través de la aplicación del MAC en sus tres etapas, donde se logró la identificación de los problemas y sus causas, el diagnóstico sobre el estado actual de los cultivos autóctonos en el sector; así como la construcción colectiva de las acciones a emprender en la propuesta para poder en un futuro no muy lejano rescatar los cultivos autóctonos en la comunidad de Tuncarta y así recuperar la sabiduría ancestral de sus habitantes.

Las principales causas que ocasionan el abandono de los cultivos autóctonos en el sector de Tuncarta son la migración, desvaloración de los cultivos nativos, falta de asesoramiento técnico por parte de las instituciones sobre manejo, desconocimiento de las bondades medicinales, nutricionales y las formas de procesamiento, entre las más importantes.

\section{Conclusiones}


Los elementos epistemológicos observados en el transcurso de las ocho sesiones realizadas en todo el proceso de intervención fueron: temor al momento de expresarse los participantes, miedo por parte del interventor a que salgan mal los talleres y temor a que las opiniones de los participantes sean equivocadas. Se logró la conciencia crítica en los moradores del sector sobre los problemas que tiene la comunidad llegando a reflexionar al momento de solucionarlos. Existe poca participación y cooperación por parte de los habitantes de Tuncarta para solventar sus principales contradicciones.

No se observa la implicación de las Instituciones públicas y privadas en el desarrollo de la comunidad, en lo referente al manejo de los cultivos autóctonos presentaría buena rentabilidad si se aplican abonos orgánicos. Sin embargo factores como la escasa concienciación de los consumidores que no dan importancia a los productos nativos, reducirían su margen de rentabilidad. A través de la aplicación del MAC en sus tres etapas se logró la identificación de los problemas y sus causas, el diagnóstico sobre el estado actual de los cultivos autóctonos en el sector; así como la construcción colectiva de las acciones a emprender en la propuesta para poder rescatar los cultivos autóctonos en la comunidad de Tuncarta y así recuperar la sabiduría ancestral de sus habitantes.

Existió el compromiso de todos los habitantes del sector para asistir a las capacitaciones organizadas en la propuesta de intervención. Los encuestados manifestaron que sí consumirían productos obtenidos del procesamiento de cultivos autóctonos, por ser algo novedoso, su alto valor nutricional, por ser productos nativos, por no poseer químicos y por su valor medicinal. Se logró en el transcurso de los ocho talleres que los participantes dirigieran las sesiones logrando de esta manera hacer trabajo comunitario, los cuales en su mayoría no sobrepasaron la hora. Las técnicas utilizadas en la presente investigación fueron los grupos focales, de reflexión, además de la aplicación de encuestas y las entrevistas a profundidad.

\section{Agradecimientos}

Nuestro agradecimiento imperecedero a los habitantes de la comunidad de Tuncarta y del Colegio Agropecuario Ñukanchik Kawsay (Nuestra Vida), quienes con su sacrificio y entrega mostrado cada semana permitieron que este trabajo llegué a su feliz término.

\section{Bibliografía}

Abrigo, P., (2012). Los cultivos autóctonos en el sector de tuncarta del cantón saraguro y su perspectiva de rescate como aporte al desarrollo comunitario. Tésis Mgs. Loja, Ec., Universidad Nacional de Loja. Área Jurídica, Social y Administrativa.

Abrigo, P. (2016). Identificación de Necesidades para Proponer el Desarrollo Turístico en la Comunidad de Tuncarta, del Cantón Saraguro de la Provincia de Loja. INNOVA Research Journal, 1(6).

Abrigo, P. (2016). La fertilización orgánica del melloco (Ullucus tuberosus L.) y su rentabilidad en la comunidad de Tuncarta. INNOVA Research Journal, 1(12). 
Calero J. (2000). Investigación cualitativa y cuantitativa. Problemas no resueltos en los debates actuales. Rev. Cubana Endocrinol; 11 (3): 192-8.

Freire, J. (2010). La investigación como herramienta para el desarrollo comunitario. Universidad Central "Martha Abrew" de la Villas, Santa Clara - Cuba.

Marchioni, M., (1999). Comunidad, participación y desarrollo. Madrid., Popular S.A.

Martínez, M. (2011). Desarrollo Sociocultural comunitario. Universidad Central "Martha Abrew" de la Villas, Santa Clara - Cuba.

Rivero, R., (2010). Intervención profesional en trabajo social y comunitario. Universidad Central "Martha Abrew" de la Villas, Santa Clara - Cuba.

Verdejo, M. E., \& Hidalgo, E. J. (2003). Diagnóstico rural participativo: Una guía práctica. Centro Cultural Poveda, Proyecto Comunicación y Didáctica. 